\title{
TINGKAT KEBUGARAN JASMANI MAHASISWA PENDIDIKAN OLAHRAGA TAHUN AKADEMIK 2019/2020 UNIVERSITAS QUALITY BERASTAGI
}

\author{
Janwar Frihasan Sinuraya \\ Universitas Quality Berastagi, email : janwarfrihasansinuraya@yahoo.com \\ Julius Boy Nesra Basgimata Barus \\ Universitas Quality Berastagi, email : boynesra@gmail.com
}

\begin{abstract}
Abstrak
Pemeliharaan kesehatan sangat penting untuk dilakukan. Semakin terpelihara kesehatan ditunjukkan dengan semakin baiknya kondisi kebugaran jasmani seseorang. Kebugaran jasmani atau kesegaran jasmani akan mendukung dalam menjalankan aktivitas sehari-hari. Peningkatan kebugaran jasmani dapat tingkatkan dengan olahraga atau kegiatan rutin. Telah banyak program peningkatan kebugaran jasmani yang dilakukan, baik itu dengan biaya yang murah dan menyenangkan. Berdasarkan uraian tersebut, diketahui bahwa kebugaran jasmani sangat penting bagi siapapun terutama bagi atlet dan mahasiswa pendidikan olahraga. Kebugaran jasmani dapat dilakukan dengan melalui serangkaian tes, seperti lari cepat 60 meter, tes gantung angkat tubuh 60 detik, tes loncat tegak, tes baring duduk 60 detik, dan tes lari dengan jarak tempuh 1200 meter. Jenis penelitian yaitu penelitian deskriptif, populasi penelitian ini mahasiswa pendidikan olahraga tahun akademik 2019/2020 Universitas Quality Berastagi sebanyak 15 orang dengan kategori usia respoden yaitu 16-19 tahun. Hasil analisis yang dilakukan pada penelitian ini diperoleh hasil bahwa peneliti memberikan kesimpulan bahwa tingkat kebugaran mahasiswa pendidikan olahraga tahun akademik 2019/2020 Universitas Quality Berastagi termasuk dalam kategori skor baik dengan jumlah mahasiswa sebanyak 9 orang (60\%) dari total keselurahan responden sebanyak 15 orang.
\end{abstract}

Kata Kunci : Tingkat Kebugaran Jasmani, Mahasiswa Pendidikan Olahraga

\begin{abstract}
Health maintenance is very important to do. The better maintained health is shown by the better condition of one's physical fitness. Physical fitness or physical fitness will support in carrying out daily activities. Improved physical fitness can be increased by exercise or routine activities. There have been many physical fitness improvement programs that have been carried out, both at cheap and pleasant costs. Based on this description, it is known that physical fitness is very important for anyone, especially for athletes and sports education students. Physical fitness can be done by going through a series of tests, such as a 60-meter sprint, a 60-second body lift test, a vertical jump test, a 60-second reclining test, and a 1200meter running test. This type of research is descriptive research, the population of this study is sports education students in the academic year 2019/2020 Quality University of Berastagi as many as 15 people with respodent age category that is 16-19 years. The results of the analysis conducted in this study showed that the researchers concluded that the fitness level of sports education students in the academic year 2019/2020 of the University of Quality Berastagi included in the category of good scores with the number of students as many as 9 people (60\%) of the total number of respondents as many as 15 people.
\end{abstract}

Keyword : The Level Of Physical Fitness 


\section{PENDAHULUAN}

Pemeliharaan kesehatan sangat penting untuk dilakukan. Semakin terpelihara kesehatan ditunjukkan dengan semakin baiknya kondisi kebugaran jasmani seseorang. Kebugaran jasmani atau kesegaran jasmani akan mendukung kemampuan untuk dapat melakukan aktivitas yang dijalankan sehari-hari (Suharjana, 2013). Kebugaran jasmani dikatakan tinggi jika mampu bertahan lama menjalankan aktivitas dibandingkan dengan yang memiliki tingkat kebugaran jasmani yang rendah.

Sudah dilakukan sejak dini untuk dapat memperkenalkan tentang pendidikan jasmani, olahraga dan kesehatan. Hal ini dapat dilihat pada peraturan yang ditetapkan oleh pemerintah dalam undang-undang Republik Indonesia (RI) nomor 11 pada tahun 1989 berisi sistem pendidikan nasional. Menurut (Solihin, Anwar, Sukandar, 2013) pada usia dini pembelajaran pendidikan jasmani dimulai, dikarenakan pada usia dini masih dalam proses perkembangan dan pertumbuhan motorik, organik, intelektual dan emosional. Sehingga disimpulkan bahwa pendidikan jasmani pada usia dini akan ikut berperan dalam membentuk karakter.

Pendidikan jasmani merupakan salah satu bagian dari pendidikan yang dalam aktivitasnya mengutamakan kegiatan fisik dan pola hidup sehat. Menurut (Utama, 2011) bahwa pendidikan jasmani sebagai proses pendidikan mengutamakan aktivitas fisik dalam menghasilkan suatu perubahan holistik bagi kualitas individu secara emosional, fisik dan mental. Sehingga pendidikan jasmani akan membentuk kebugaran jasmani dalam kegiatannya.
Kebugaran jasmani adalah kemampuan tubuh dalam menjalankan aktivitas fisik tanpa menimbulkan keletihan secara berlebihan. Kebugaran jasmani pada diri seseorang sangat dipengaruh oleh kondisi kegiatan fisik yang dilakukan. Kondisi fisik sangat penting dan faktor penting bagi seseorang untuk melakukan kegiatan sehari-hari. Sehingga kebugaran jasmani baik akan memberikan dampak dalam menjalankan kegiatan menjadi lebih segar dan tidak cepat lelah.

Bagi mahasiswa pendidikan olahraga kebugaran jasmani menjadi syarat mutlak, dikarenakan mahasiswa pendidikan olahraga dalam perkuliahan lebih banyak dilapangan dan menggunakan aktivitas fisik dibandingkan dengan teori di dalam kelas. Oleh karena itu, kebugaran jasmani menjadi faktor mutlak yang harus dimiliki. Sehingga berbagai upaya dilakukan untuk mempertahankan atau meningkatkan kebugaran jasmani tersebut. Namun pada kenyatannya, berdasarkan observasi diketahui bahwa terdapat banyak kendala kebugaran jasmani dalam pendidikan jasmani, seperti kondisi lingkungan, asupan nutrisi makanan, sarana dan prasarana, jenis kelamin, kesukaan/minat, pelaksanaan pembelajaran. Peningkatan kebugaran jasmani dapat tingkatkan dengan olahraga atau kegiatan rutin. Telah banyak program peningkatan kebugaran jasmani yang dilakukan, baik itu dengan biaya yang murah dan menyenangkan. Olahraga menurut (Yane, Arifin dan Fuzita, 2016) bahwa kegiatan olahraga sangat penting dilakukan oleh seorang atlet untuk menggapai suatu prestasi, tes kebugaran rutin dilakukan oleh atlet agar diketahui letak kekurangan atlet tersebut dan dapat dicari solusi yang terbaik. 
Berdasarkan uraian tersebut, diketahui bahwa kebugaran jasmani sangat penting bagi siapapun terutama bagi atlet dan mahasiswa pendidikan olahraga. Kebugaran jasmani dapat dilakukan dengan melalui serangkaian tes, seperti lari cepat 60 meter, tes gantung angkat tubuh 60 detik, tes loncat tegak, tes baring duduk 60 detik, dan tes lari dengan jarak tempuh 1200 meter. Pada mahasiswa pendidikan olahraga di Universitas Quality Berastagi ditemukan permasalahan belum pernah dilakukan tes kebugaran jasmani mahasiswa semester I ini. Sehingga perlu dilakukan serangkaian tes bagi mahasiswa tahun akademik 2019/2020 dengan jumlah responden sebanyak 15 orang mahasiswa agar dapat diketahui sejauh mana kebugaran jasmani mahasiswa tersebut. Sehingga jika terdapat mahasiswa yang dianggap hasil tes kurang baik dapat diberikan solusi agar dapat sama dengan mahasiswa lainnya. Data tes kebugaran sangat diperlukan untuk kepentingan proses perkuliahan, karena mahasiswa pendidikan olahraga dituntut untuk dapat selalu menjaga kebugaran jasmani pada diri mereka. Sehingga tujuan penelitian ini adalah untuk menganalisis tingkat kebugaran jasmani mahasiswi pendidikan olahraga tahun akademik 2019/2020 Universitas Quality Berastagi.

Berbagai macam tes untuk mengukur tingkat kebugaran jasmani. Adapun tujuan dari dilakukan tes kebugaran jasmani yaitu untuk menganalisis kebugaran jasmani pada responden. Beberapa alat yang dipergunakan untuk tes kebugaran jasmani adalah palang tunggal dan stopwatch. Menurut Widaninggar W., (2010:3) bahwa dalam melakukan tes tingkat kebugaran jasmani terdapat lima rangkaian yang dilakukan. Adapun kelima rangkaian disesuaikan dengan penelitian yang dilakukan oleh tim peneliti yaitu pada usia 16-19 tahun putra yaitu tes lari cepat 60 meter, tes gantung angkat tubuh 60 detik, tes baring duduk 60 detik, tes loncat tegak, tes lari 1200 meter.

\section{Menurut Mukholid}

(2006)

pengukuran tes kebugaran jasmani sangat penting. Melalui tes kebugaran jasmani akan diketahui kebugaran responden yang diamati. Setelah dilakukan tes kebugaran jasmani maka akan diperoleh hasil yang akan di tinjau terlebih dahulu. Jika hasil yang diperoleh rendah dari kategori atau klasifikasi yang ditentukan, maka akan dicari solusi terhadap permasalahan tersebut.

\section{METODOLOGI PENELITIAN}

Lokasi penelitian ini dilakukan di Universitas Quality Berastagi Kabupaten Karo Provinsi Sumatera Utara. Waktu pelaksanaan penelitian dilakukan 1 kali pertemuan.

Metode pada penelitian ini adalah deskriptif kuantitatif. Menurut (Tegeh dan Kirna, 2013) penelitian deskriptif adalah suatu fenomena yang menggambarkan suatu peristiwa tertentu yang bahkan sedang berlangsung. Tujuan penelitian deskriptif yaitu untuk memberikan gambaran sifat terhadap suatu situasi sementara menggambarkan sebab akibat terhadap suatu gejala atau fenomena. Populasi merupakan jumlah keseluruhan dari objek yang diamati berdasarkan pada karakteristik yang akan diteliti. Populasi pada penelitian ini adalah mahasiswa pendidikan olahraga tahun akademik 2019/2020 Universitas Quality Berastagi dengan jumlah responden sebanyak 15 orang dengan karakteristik usia yaitu 16-19 tahun. Adapun teknik pengumpulan data yaitu suatu cara yang dilakukan seorang peneliti untuk memperoleh data yang sesuai dengan tujuan penelitian. Pada 
penelitian ini teknik pengumpulan data untuk menjawab tujuan penelitian yaitu dengan bentuk tes kebugaran jasmani Indonesia (TKJI) yang terdiri dari tes lari cepat 60 meter, tes gantung angkat tubuh 60 detik, tes baring duduk 60 detik, tes loncat tegak, tes lari 1200 meter.

\section{HASIL DAN PEMBAHASAN}

Tes kebugaran jasmani Indonesia (TKJI) merupakan suatu rangkaian tes yang digunakan untuk mengukur kebugaran jasmani berdasarkan pada tingkat usia responden. Jenis-jenis tes kebugaran jasmani Indonesia atau yang biasa disingkat dengan tkji dikategorikan menjadi berdasarkan usia yaitu : tes kebugaran jasmani Indonesia (TKJ) pada usia 6-9 tahun, tkji pada usia 10-12 tahun, tkji pada usia 13-15 tahun dan tkji pada usia 16-19 tahun.

Hasil penelitian ini merupakan suatu kajian lapangan tentang kebugaran jasmani mahasiswa Pendidikan Olahraga Tahun Akademik 2019/2020 Universitas Quality Berastagi. tes lari cepat 60 meter, tes gantung angkat tubuh 60 detik, tes baring duduk 60 detik, tes loncat tegak, tes lari 1200 meter. Menurut (Prakoso dan Hartoto, 2015) bahwa tingkat kebugaran jasmani sangat penting, karena kebugaran jasmani berguna dalam menjalankan aktivitas sehari-hari seseorang.

Tingkat kebugaran jasmani tidak mengenal umur, artinya tingkat jasmani sangat dibutuhkan baik itu bagi generasi muda atau generasi tua. Jika tingkat kebugaran jasmani yang yang rendah akan menyebabkan kemampuan dalam menjalankan aktivitas menjadi rendah pula. Sejalan dengan pendapat (Muhammadiah, 2011), kebugaran jasmani sangat berhubungan dengan segala aktivitas manusia dalam melakukan pekerjaan dan olah gerak.
Kebugaran jasmani mencakup aspek kesehatan dan performa. unsurunsur kebugaran jasmani meliputi kekuatan otot, daya tahan otot, daya tahan jantung, dan paru-paru, fleksibilitas, koordinasi, agilitas, kecepatan dan keseimbangan. Kebugaran jasmani bermanfaat bagi pekerjaan manusia, artinya tingkat kebugaran jasmani bagi orang dewasa dan anak-anak sangat individual.

Hasil analisis tes lari 60 meter pada mahasiswa pendidikan olahraga tahun akademik 2019/2020 universitas quality berastagi. Tes lari 60 meter pada tes kebugaran jasmani bertujuan untuk mengukur kecepatan lari mahasiswa. Alat yang digunakan pada tes lari 60 meter terdiri dari bendera, tiang, peluit, stopwatch, kapur, dan formulir.

Hasil analisis tes lari 60 meter dengan jumlah responden sebanyak 15 orang, diperoleh hasil skor tercepat yaitu 6,55 detik sedangkan skor terendah yaitu 8,4 detik (Tabel 1 ) berarti masuk dalam golongan nilai 3-4 hal ini senada dengan penelitian yang dilakukan oleh (Muspita, Kamarudin dan Fernando, 2018) bahwa kebugaran jasmani.

Pada mahasiswa mahasiswa penjaskesrek semeter I FKIP UIR Tahun 2015/2016 termasuk kelompok baik dengan nilai rata-rata yaitu skor 3-4, sehingga dapat disimpulkan bahwa mahasiswa memiliki cadangan tenaga yang dapat digunakan untuk melakukan aktivitas lainnya. Lebih lanjut menurut pendapat (Elzandri dan Dewi, 2018), tingkat kebugaran jasmani pada individu dapat dilihat melalui kemampuan dalam menjalankan aktivitas fisik tanpa mengalami kelelahan yang berlebihan. Sebaran hasil analisis tes lari 60 meter pada mahasiswa pendidikan olahraga tahun akademik 2019/2020 Universitas Quality Berastagi dapat dilihat pada tabel 1 berikut ini. 
Tabel 1. Sebaran frekuensi hasil tes lari 60 meter pada mahasiswa

\begin{tabular}{|c|c|c|c|}
\hline Nilai & Hasil Test & Frekuensi & $\begin{array}{c}\text { Persen } \\
\text { tasi } \\
(\%) \\
\end{array}$ \\
\hline 5 & $\begin{array}{c}\mathrm{Sd}-7,2 \\
\text { detik }\end{array}$ & 3 & 20,00 \\
\hline 4 & $\begin{array}{c}7,3-8,3 \\
\text { detik }\end{array}$ & 8 & 53,33 \\
\hline 3 & $\begin{array}{c}8,4-9,6 \\
\text { detik }\end{array}$ & 4 & 26,67 \\
\hline 2 & $\begin{array}{c}9,7-11,0 \\
\text { detik }\end{array}$ & 0 & 0,00 \\
\hline 1 & $\begin{array}{l}11,1- \\
\text { detik }\end{array}$ & 0 & 0,00 \\
\hline \multicolumn{2}{|c|}{ Jumlah } & 15 & 100,00 \\
\hline
\end{tabular}

Sebaran hasil tes lari 60 meter yang dilakukan mahasiswa pendidikan olahraga Universitas Quality Berastagi yaitu kategori Sd $-7,2$ detik sebanyak 3 orang (20\%), kategori 7,3 - 8,3 detik sebanyak 8 orang $(53,33 \%)$, kategori $8,4-9,6$ detik sebanyak 4 orang $(26,67 \%)$.

Hasil Analisis Tes Gantung Angkat Tubuh 60 detik Mahasiswa Pendidikan Olahraga Tahun Akademik 2019/2020 Universitas Quality Berastagi.

Kemampuan gantung sikut tekuk digunakan sebagai awal kekuatan lengan dan merupakan tes diagnostik koordinasi gerakan. Pada usia 19-21 perkembangan kemampuan gantung sikut tekuk yang efektif memiliki manfaat yang besar disamping membentuk otot lengan, juga mempercepat pertumbuhan tinggi badan (Nosa, 2013).

Tes gantung angkat tubuh 60 menit memiliki tujuan yaitu untuk mengukur ketahan dan kekuatan otot bahu dan lengan. Alat yang digunakan untuk melaksanakan lantai yang rata dan bersih, palang tunggal yang disesuaikan dengan ketinggian peserta tes, pipa pegangan yang tebuat dari besi dengan ukuran pipa yaitu $3 / 4$ inchi, kapur, stopwatch serta alat tulis.

Berdasarkan hasil tes gantung angkat tubuh pada mahasiswa pendidikan olahraga tahun akademik 2019/2020 Universitas Quality Berastagi dengan jumlah responden sebanyak 15 orang, maka diperoleh hasil bahwa skor gantung angkat tubuh tertinggi 25,05 detik dan terendah 11,61 detik. Sebaran data hasil angkat tubuh dapat dilihat pada tabel 2 .

Tabel 2. Distribusi Frekuensi Hasil Tes Gantung AngkatTubuh 60 detik

\begin{tabular}{|c|c|c|c|}
\hline $\begin{array}{l}\text { Nil } \\
\text { ai }\end{array}$ & Hasil Test & $\begin{array}{c}\text { Frek } \\
\text { uen } \\
\text { si }\end{array}$ & $\begin{array}{c}\text { Persentasi } \\
\text { (\%) }\end{array}$ \\
\hline 5 & $\mathrm{Sd}-7,2$ detik & 3 & 20,00 \\
\hline 4 & $7,3-8,3$ detik & 8 & 53,33 \\
\hline 3 & $8,4-9,6$ detik & 4 & 26,67 \\
\hline 2 & $\begin{array}{c}9,7-11,0 \\
\text { detik }\end{array}$ & 0 & 0,00 \\
\hline 1 & $11,1-$ detik & 0 & 0,00 \\
\hline \multicolumn{2}{|r|}{ Jumlah } & 15 & 100,00 \\
\hline
\end{tabular}

Sebaran hasil tes yaitu kategori 23,8-27,8 sebanyak 1 orang (6,67\%), kategori 19,7-23,7 sebanyak 1 orang (6,67\%), kategori 15,5-19,6 sebanyak 10 orang (66,67\%), kategori 11,5-15,5 sebanyak 3 orang (20\%). Menurut (Darmawan, 2017) bahwa kemampuan gantung sikut tekuk pada mahasiswa penjaskesrek mencapai hasil yang baik dengan dibuktikan tes gantung sikut tekuk, dengan skor rata-rata 4 artinya bahwa tingkat kebugaran jasmani pada mahasiswa berada pada tarap normal. Hasil Analisis Tes Baring Duduk (Sit-Up) selama 60 Detik Mahasiswa Pendidikan Olahraga Tahun Akademik 2019/2020 Universitas Quality Berastagi

Tes baring duduk (Sit-Up) bertujuan untuk mengukur daya kekuatan dan kemampuan otot perut. Pada penelitian ini, alat yang digunakan untuk melaksanakan tes baring duduk yaitu lapangan dengan kondisi rata dan bersih, alat tulis, stopwatch. 
Latihan kebugaran jasmani dengan melakukan latihan sit-up selama 60 menit memberikan nilai yang positif pada mahasiswa, di samping itu manfaatnya adalah membentuk otot perut dan otot leher serta menjadi salah satu predictor untuk meningkatkan kebugaran jasmani.

Berdasarkan hasil tes baring duduk pada mahasiswa pendidikan olahraga tahun akademik 2019/2020 Universitas Quality Berastagi dengan jumlah responden sebanyak 15 orang, maka diperoleh skor tes baring duduk yaitu dengan perolehan nilai tertinggi 35 kali dan terendah 16 kali. Lebih lanjut dijabarkan hasil analisis bahwa berdasarkan masing-masing kategori hasil tes yaitu pada kategori 28-35 sebanyak 9 orang atau $60 \%$, kategori $24-27$ sebanyak 1 orang atau 6,67\%, kategori 20-23 sebanyak 3 orang atau $20 \%$, kategori $16-$ 19 sebanyak 2 orang atau 13,33\%. Sebaran data hasil tes baring duduk (situp) selama 60 dapat dilihat pada tabel 3.

Tabel 3. Distribusi Frekuensi Data Tes Baring Duduk (Sit-Up) selama 60 Detik

\begin{tabular}{c|c|c|c}
\hline $\begin{array}{c}\text { Nila } \\
\text { i }\end{array}$ & Hasil test & Frekuensi & $\begin{array}{c}\text { Persent } \\
\text { ase } \\
\mathbf{( \% )}\end{array}$ \\
\hline 5 & $28-35$ & 9 & 60,00 \\
\hline 4 & $24-27$ & 1 & 6,67 \\
\hline 3 & $20-23$ & 3 & 20,00 \\
\hline 2 & $16-19$ & 2 & 13,33 \\
\hline 1 & $12-15$ & 0 & 0.00 \\
\hline \multicolumn{2}{r|}{ Jumlah } & 15 & 100.00 \\
\hline
\end{tabular}

Hasil Analisis Tes Loncat Tegak (Vertical Jump) Mahasiswa Pendidikan Olahraga Tahun Akademik 2019/2020 Universitas Quality Berastagi

Tes loncat tegak (Vertical Jump) bertujuan mengukur kemampuan daya ledak atau tenaga eksplosif. Pada penelitian ini, alat yang digunakan untuk melakukan tes tersebut terdiri dari kapur, alat tulis, papan dengan skala $30 \times 150 \mathrm{~cm}$, penghapus.

Loncat tegak merupakan aktivitas fisik yang dilakukan dengan mengangkat kedua kaki setinggi-tingginya pada posisi tetap di tempat atau berpindah-pindah. Tujuan tes loncak tegak adalah untuk mengukur kemampuan otot tungkai, adapun prosedur dalam pelaksanaan loncat tegak yaitu diawali dengan berdiri tegak dekat dinding, lalu posisi bertumpu pada kedua kaki dengan posisi salah satu lengan berada pada dinding lalu diluruskan keatas, selanjutnya meloncat dengan kemampuan setinggi mungkin untuk dapat mencapai papan skala dengan menggunakan tangan dan mendarat dengan kedua kaki. Menurut (Juniarsyah, Apriantono dan Adnyana, 2017) mengkalasifikasikan komponen kebugaran jasmani tersebut terdiri dari kecepatan, daya tahan, daya ledak, keseimbangan, kekuatan.

Pada tes loncat tegak alat yang digunakan berupa papan dengan skala lebar $30 \mathrm{~cm}$ dan panjang $150 \mathrm{~cm}$, dengan pemberian jarak antara skala yaitu sebesar $1 \mathrm{~cm}$ pada masing-masing papan. Selanjutnya papan skala yang telah dibuat tersebut ditempelkan pada tembok dengan skala 0 dan lantai $150 \mathrm{~cm}$. Setelah dilakukan prosedur kegiatan maka akan diperoleh nilai dan selisih antara raihan tertinggi pada pengukuran pertama tidak melakukan melompat yaitu hasil vertical jump.

Berdasarkan hasil tes loncat tegak pada mahasiswa pendidikan olahraga tahun akademik 2019/2020 Universitas Quality Berastagi dengan jumlah responden sebanyak 15 orang, maka hasil analisis dengan nilai tertinggi tes loncat yaitu $47 \mathrm{~cm}$ dan skor nilai terendah yaitu $41 \mathrm{~cm}$. Sebaran hasil tes yaitu Kategori 47-48 sebanyak 4 orang atau $26,67 \%$, kategori 45-46 sebanyak 5 orang atau 
33,33\%, kategori 43-44 sebanyak 5 orang atau $33,33 \%$ dan kategori $41-42$ sebanyak 1 orang atau $6,67 \%$. Untuk lebih lanjut, hasil analisis dapat dilihat pada tabel 4 .

Tabel 4. Hasil Analisis Data Tes

\begin{tabular}{c|c|c|c}
\multicolumn{4}{|c}{ Loncat Tegak } \\
\hline Nilai & $\begin{array}{c}\text { Hasil } \\
\text { test }\end{array}$ & Frekuensi & $\begin{array}{c}\text { Persentase } \\
\text { (\%) }\end{array}$ \\
\hline 5 & $47-48$ & 4 & 26,67 \\
\hline 4 & $45-46$ & 5 & 33,33 \\
\hline 3 & $43-44$ & 5 & 33,33 \\
\hline 2 & $41-42$ & 1 & 6,67 \\
\hline 1 & $39-40$ & 0 & 0.00 \\
\hline & Jumlah & 15 & 100,00 \\
\hline
\end{tabular}

Tes lari 1200 meter bertujuan untuk melakukan pengukuran daya tahan jantung dan paru-paru, tingkat pernafasan dan peredaran darah di tubuh. Pada penelitian ini, alat yang digunakan yaitu stopwatch, lintasan untuk lari, tiang, peluit, bendera dan alat tulis.

Hasil analisis pada tes lari 1200 meter dengan jumlah responden sebanyak 15 orang. Maka diperoleh hasil nilai tertinggi mahasiswa Universitas Quality Berastagi pada tes lari 1200 meter adalah 7,58 menit dan nilai terendah yaitu 11,27 menit. Hasil tes lari 1200 meter dikategorikan pada 3'14" sebanyak 5 orang atau 33,33\%, kategori 3'15-4'25" sebanyak 6 orang atau 40\%, kategori 4'26" - 5'12" sebanyak 3 orang atau $20 \%$ dan kategori 5'13 - 6'33" sebanyak 1 orang atau 6,67 . Untuk lebih jelas nya dapat dilihat pada tabel 5 .

Tabel 5. Hasil Tes Lari 1200 Meter

\begin{tabular}{c|c|c|c}
\hline Nilai & $\begin{array}{c}\text { Hasil } \\
\text { test }\end{array}$ & Frekuensi & $\begin{array}{c}\text { Persentase } \\
\text { (\%) }\end{array}$ \\
\hline 5 & $3^{\prime} 14^{\prime \prime}$ & 5 & 33,33 \\
\hline 4 & $\begin{array}{c}3^{\prime} 15- \\
4^{\prime} 25^{\prime \prime}\end{array}$ & 6 & 40,00 \\
\hline 3 & $4^{\prime} 26^{\prime \prime}-$ & 3 & 20,00 \\
\hline
\end{tabular}

\begin{tabular}{c|c|c|c}
\hline & $5^{\prime} 12^{\prime \prime}$ & & \\
\hline 2 & $5^{\prime} 13-$ & 1 & 6,67 \\
& $6^{\prime} 33^{\prime \prime}$ & & \\
\hline 1 & Dibawah & 0 & 0.00 \\
& $6^{\prime} 33^{\prime \prime}$ & & \\
\hline \multicolumn{2}{r}{ Jumlah } & 15 & 100,00 \\
\hline
\end{tabular}

Data Hasil Tes Kesegaran Jasmani Mahasiswi Pendidikan Olahraga Tahun Akademik 2019/2020 Universitas Quality Berastagi

Hasil yang diperoleh dari melakukan tes kebugaran jasmani pada mahasiswa pendidikan olahraga tahun akademik 2019/2020 Universitas Quality Berastagi dengan klasifikasi nilai baik yaitu sebanyak 1 orang (6.67), baik sebanyak 9 orang $(60 \%)$, klasifikasi sedang sebanyak 4 orang $(26,67 \%)$, klasifikasi kurang sebanyak 1 orang (6,67\%) dan tidak terdapat pada klasifikasi kurang sekali. Sehingga dapat disimpulkan bahwa tingkat kebugaran jasmani termasuk dalam kategori sedang. Untuk lebih rinci dapat dilihat pada tabel 6 dan grafik hasil tes kebugaran jasmani mahasiswi pendidikan olaharaga tahun Akademik 2019/2020 Universitas Quality Berastagi dapat dilihat pada gambar 1 .

Tabel 6. Klasifikasi Hasil Tes Kesegaran Jasmani Mahasiswi Pendidikan Olahraga Tahun Akademik 2019/2020 Universitas Quality Berastagi

\begin{tabular}{c|c|c|c}
\hline Klasifikasi & Skor & $\begin{array}{c}\text { Freku } \\
\text { ensi }\end{array}$ & $\begin{array}{c}\text { Persenta } \\
\text { se (\%) }\end{array}$ \\
\hline Baik Sekali & $22-25$ & 1 & 6.67 \\
\hline Baik & $18-21$ & 9 & 60.00 \\
\hline Sedang & $14-17$ & 4 & 26.67 \\
\hline Kurang & $13-10$ & 1 & 6.67 \\
\hline $\begin{array}{c}\text { Kurang } \\
\text { Sekali }\end{array}$ & $5-9$ & 1 & 6.67 \\
\hline \multicolumn{2}{c|}{ Jumlah } & 15 & 100,00 \\
\hline
\end{tabular}




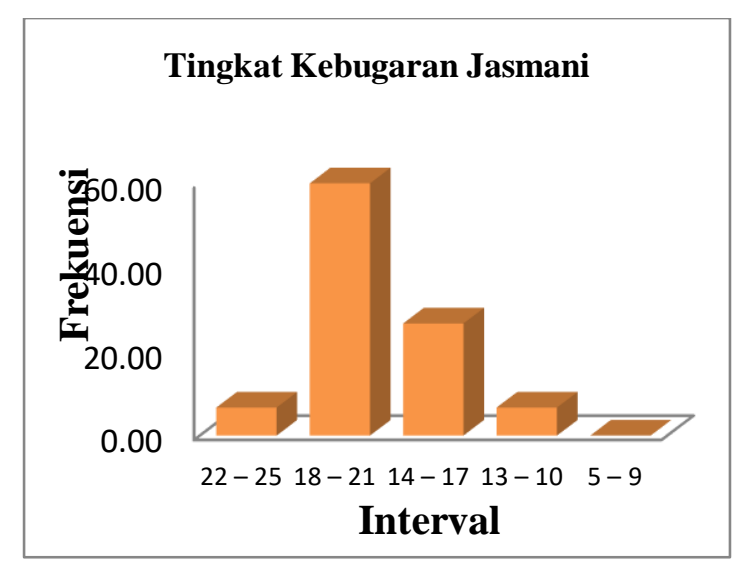

Gambar 1. Grafik Hasil Tes Kebugaran

Pada penelitian kebugaran jasmani penelitian ini pada kelompok usia 16-19 tahun dengan beberapa tes yang dilakukan. Adapun tes yang dilakukan peneliti untuk mendapatkan data tingkat kebugaran jasmani mahasiswa pendidikan olahraga tahun akademik 2019/2020 Universitas Quality Berastagi diperoleh nilai pada tes lari 40 meter diperoleh hasil dengan kategori baik, pada tes gantung angkat tubuh 30 detik diperoleh hasil dengan kategori sedang, tes baring duduk 60 detik diperoleh hasil baik sekali, tes loncat tegak diperoleh kesimpulan baik dan sedang, tes lari 1200 meter disimpulkan hasil baik. Sehingga pada tes kebugaran jasmani pada mahasiswa pendidikan olahraga Universitas Quality Berastagi secara keseluhan dapat dikategorikan dengan hasil yang baik. Adapun untuk klasifikasi yang masih kurang sekali perlu dilakukan perbaikan agar dapat meningkatkan kebugaran jasmani.

Berdasarkan tabel 6 dapat dilihat hasil penelitian yang telah dilakukan, diambil kesimpulan bahwa melalui Tes Kebugaran Jasmani Indonesia (TKJI) pada mahasiswa pendidikan olahraga tahun akademik 2019/2020 Universitas Quality Berastagi meningkatkan kebugaran jasmani pada mahasiswa kategori baik.
Pelaksanaan kegiatan perkuliahan dilapanagan telah mampu memberikan dampak yang baik bagi kebugaran jasmani mahasiswa pendidikan olahraga tahun akademik 2019/2020 Universitas Quality Berastagi. Perkuliahan yang diberikan melalui pola latihan fisik dengan sarana prasarana yang tersedia, serta kondisi alam yang cenderung mudah mengalami perubahan pada saat dilakukan kegiatan keolaragaan. Adapun kondisi alam tersebut yaitu perubahan cuaca di berastagi terkadang dapat hujan tiba-tiba. Akan tetapi kondisi tersebut tetap dapat di atasi oleh mahasiswa.

Kebugaran jasmani berkaitan dengan kemampuan seseorang untuk dapat menjalankan aktivitas secara efektif dan efisien tanpa menimbulkan kelelahan yang berarti. Artinya setelah orang tersebut melakukan aktivitas maka orang tersebut tetap dapat melakukan aktivitas lain setelah melakukan jeda untuk dapat beristirahat. Tingkat kebugaran jasmani berupa kondisi fisik yang baik akan menunjang aktivitas yang baik pula. Kondisi cuaca yang sering mengalami perubahan jika diimbangi dengan kondisi kebugaran jasmani terjaga maka segala kegiatan yang dilakukan dapat berjalan dengan lancer. Sehingga dapat dikatakan bahwa terjaganya kondisi kebugaran jasmani yang menjadikan seseorang lebih produktif dalam beraktivitas.

Melihat hasil penelitian tersebut hendaknya pola pembinaan dosen terhadap mahasiswa untuk mempertahankan kondisi kebugaran jasmani tetap terjaga. Jika diperlukan dapat memberikan teori dan praktek yang dapat mampu meningkatkan lebih baik lagi kebugaran mahasiswa tersebut, terutama jika mahasiswa tersebut merupakan atlet kabupaten/provinsi. 


\section{KESIMPULAN DAN SARAN Simpulan}

Berdasarkan hasil penelitian dan analisis data yang telah dilakukan oleh peneliti, maka peneliti memberikan kesimpulan bahwa tingkat kebugaran mahasiswa pendidikan olahraga tahun akademik 2019/2020 Universitas Quality Berastagi termasuk dalam kategori skor baik dengan jumlah mahasiswa sebanyak 9 orang (60\%) dari total keselurahan responden sebanyak 15 orang.

Saran

Adapun saran yang berikan oleh peneliti, jika ingin mempertahankan atau meningkatan kebugaran jasmani yaitu melalui kegiatan rutin berolahraga, menjaga pola makan yang sehat dan istirahat yang cukup.

\section{DAFTAR PUSTAKA}

Al-Jamil, A. H., \& Sugihartono, T. (2018). Analisis Tingkat Kebugaran Jasmani Siswa Pendidikan Pondok Pesantren Di Kota Bengkulu. Kinestetik, 2(1), 118-125.

Darmawan, I. (2017). Upaya meningkatkan kebugaran jasmani siswa melalui penjas. Prosiding Seminar Nasionalprofesionalisme Tenaga Profesi Pjok,444-453.

Elzandri, R. Dewi, K. (2018). Profil kebugaran jasmani pada mahasiswa Fakultas Kedokteran Universitas Tarumanagara angkatan 2012, Tarumanagara Medical Journal 1(1): 151-156.

Firmana, I. (2018). Kontribusi Kegiatan Hiking Terhadap Kebugaran Jasmani Anak Perempuan Yang Gemar Bermain Futsal. JUARA: Jurnal Olahraga. doi: 10.33222/juara.v3i1.214.

Juniarsyah, A. D., Apriantono, T. and Adnyana, I. K. (2017). Karakteristik Fisiologi Pemain Futsal Profesional Dalam Dua Pertandingan Berturut-
Turut. Jurnal Sains Keolahragaan dan Kesehatan. doi: 10.5614/jskk.2017.2.2.1.

Muhammadiah. (2011). Pengaruh Metode Latihan Lari Percepatan Dan Lari Interval Terhadap Keterampilan Bermain Sepakbola. Jurnal Magister Administrasi Pendidikan. 3(3) 87-101 Muspita, M., Kamarudin, K. Fernando, R. (2018). Profil Kebugaran Jasmani Mahasiswa Penjaskesrek Semeter I FKIP UIR Tahun 2015/2016. Jurnal. Sport AREA. 3(1);https://doi.org/10.25299/sporta rea.2018.vol3(1).1306

Prakoso, D. P. and Hartoto, S. (2015). Pengukuran Tingkat Kebugaran Jasmani Terhadap Siswa Yang Mengikuti Ekstrakulikuler Bolavoli di SMS DR.Soetomo Surabaya. Jurnal Pendidikan Olahraga dan Kesehatan.3(1); 9 - 13.

Nosa AS, Faruk M. (2013). Survei Tingkat Kebugaran Jasmani Pada Pemain Persatuan Sepakbola Indonesia Lumajang. Jurnal Prestasi Olahraga.1(1);1-8.

Prasetio, E., Sutisyana, A., \& Ilahi, B. R. (2017). Tingkat Kebugaran Jasmani Berdasarkan Indeks Massa Tubuh Pada Siswa SMP Negeri 29 Bengkulu Utara. Kinestetik, 1(2).

Saputra, S. (2019). Studi Kebugaran Jasmani Menggunakan Metode Harvard Step Tes Pada Mahasiswa Penjas Semester Vi Universitas Bengkulu Tahun Akademik 20182019. Kinestetik, 3(2), 193-197.

Solihin, M.R.D., Anwar.F., Sukandar, D. (2013). Kaitan Antara Status Gizi,Perkembangan Kognitif, Dan Perkembangan Motorik Pada Anak Usia Prasekolah', Penelitian Gizi dan Makanan.

Suharjana (2013). Analisis Program Kebugaran Jasmani Pada PUSATPusat Kebugaran Jasmani Di 
Yogyakarta. MEDIKORA.

Tegeh, I. M. and Kirna, I. M. (2013). Pengembangan Bahan Ajar Metode Penelitian Pendidikan Dengan Addie Model. Jurnal Ika.

Utama, A. M. B. (2011) 'Pembentukan Karakter Anak Melalui Aktivitas Bermain Dalam Pendidikan Jasmani', Pendidikan Jasmani Indonesia.

Yane, S., Arifin, Z. Fuzita, M. (2016) 'Analisis Tingkat Kesegaran Jasmani Mahasiswa Program Studi Penjaskesrek IKIP PGRI Pontianak', jurnal Pendidikan oOahraga.

Widaninggar, W. (2010). Tes kesegaran Jasmani Indonesia Untuk Anak Umur 10-12 Tahun. Jakarta: Pusat Pengembangan Kualitas Jasmani. 